\title{
AVALIAÇÃO DA INTRODUÇÃO DA CRIAÇÃO RACIONAL DE MELIPONA FASCICULATA (APIDAE: MELIPONINA), ENTRE OS AGRICULTORES FAMILIARES DE BRAGANÇA - PA, BRASIL
}

\author{
Giorgio Cristino Venturieri ${ }^{1}$ - Vanessa de Fátima Oliveira Raiol ${ }^{2}$ - Charles André Barbosa Pereira ${ }^{3}$
}

Biota Neotropica v3 (n2) - http://www.biotaneotropica.org.br/v3n2/pt/abstract?article+BN00103022003

\author{
Recebido em: 28/03/2003
}

Publicado em: 01/08/2003

\begin{abstract}
1 Embrapa Amazônia Oriental, C. Postal 48, Belém-PA, Brasil, CEP: 66.017-970; Pesquisador; giorgio@ cpatu.embrapa.br. 2 UFRA, C. Postal 917, Belém-PA, Brasil, CEP: 66.077-550; Acadêmica de Agronomia; vanessaraiol@yahoo.com.br. 3 Associação Comunitária São Sebastião, Cocal do Tauá, CEP: 68.786-000, Sto. Antônio do Tauá-PA, Brasil; Téc Agrícola stotaua@yahoo.com.br.
\end{abstract}

\begin{abstract}
Meliponiculture, the name given to stingless bee keeping, is a practical example of the concepts of diversification of sustainable use in Amazonia. It is an activity that can be integrated into forestry, fruit crop plantation and short cycle cultivar and can contribute through pollination to the increase of the agricultural production and regeneration of natural vegetation. The objective of this work was to evaluate the introduction of management techniques for the bee keeping of the bee known as uruçu-cinzenta (Melipona fasciculata) among the traditional beekeepers in Bragança, Pará State, Brazil. Using participative methods, from June to December of 2002, 30 families of bee, in rustic bee boxes, were replaced for boxes adapted to improve colony multiplication and increase honey production. Traditional method are described, evaluated and compared with the new method. Results demonstrated the new system to be efficient and economically viable, increasing the amount of honey obtained, facilitating crop yield and producing honey under stricter conditions of hygiene. The blooming period coincides with the dry period, in the area ranging from June to December. The largest honey production occurred, however, between August and November. The most important botanical species in the constitution of the honeys include: cashew (Anacardium occidentale - Anacardiaceae), cashew-açu (A. giganteum - Anacardiaceae), mangrovesiriuba (Avicennia nitida - Avicenniaceae), sapateira (Miconia minutiflora - Melastomataceae) and lacre (Vismia guianensis - Clusiaceae). The adopted method was well accepted, piquing interest of experienced creators' as well as of the community in general.
\end{abstract}

Key words: Meliponiculture, Bee, Family agriculture, Sustainable management, Amazon.

\section{Resumo}

Meliponicultura, nome dado à criação de abelhas indígenas sem ferrão, se enquadra perfeitamente dentro dos conceitos de diversificação e uso sustentado da terra da Amazônia. É uma atividade que pode ser integrada a plantios florestais, de fruteiras e de culturas de ciclo curto, podendo contribuir, através da polinização, com o aumento da produção agrícola e regeneração da vegetação natural. Este trabalho teve por objetivo avaliar a introdução de técnicas de manejo para a criação racional da espécie uruçu-cinzenta (Melipona fasciculata) entre os criadores tradicionais de abelhas em Bragança, PA, Brasil. Nos meses de junho a dezembro de 2002, de forma participativa com os criadores, foi realizada a transferência de 30 famílias de abelhas de caixas rústicas para caixas de criação racional. São descritas e avaliadas práticas tradicionais de manejo, comparando-as com as vantagens da adoção do método de criação racional. O sistema demonstrou ser bastante eficiente e economicamente viável, aumentando a quantidade de mel obtida, facilitando a sua colheita e produzindo mel com mais higiene. O período de maior floração coincide com o de menores índices pluviométricos, em que na região vão de junho a dezembro. A maior produção de mel concentra-se, entretanto, de agosto a novembro. As espécies botânicas locais mais importantes na constituição dos méis são: caju (Anacardium occidentale - Anacardiaceae), caju-açu (A. giganteum Anacardiaceae), siriuba (Avicennia nitida - Avicenniaceae), sapateira (Miconia minutiflora - Melastomataceae) e lacre (Vismia guianensis - Clusiaceae), entre outras. O método adotado foi bem aceiro, despertando o interesse de criadores experientes e da comunidade em geral.

Palavras-chave: Meliponicultura, Abelha, Agricultura Familiar, Manejo sustentado, Amazônia 


\section{Introdução}

A meliponicultura, nome dado à criação de abelhas da subtribo MELIPONINA (também conhecidas como abelhas indígenas sem ferrão) (Siveira et al. 2002), se enquadra perfeitamente dentro dos conceitos de diversificação e uso sustentado da terra da Amazônia. Os meliponíneos são abelhas dóceis, de fácil manejo e necessitam de pouco investimento para a sua criação. É uma atividade que pode ser integrada a plantios florestais, de fruteiras e de culturas de ciclo curto, podendo contribuir, através da polinização, com o aumento da produção agrícola e regeneração da vegetação natural.

Apesar da existência de uma vasta literatura sobre diversos aspectos da biologia das abelhas sem ferrão brasileiras (Soares \& Jong 1992, Heard 1999), poucas são as publicações que têm por objetivo investigar o potencial econômico dos meliponíneos no Brasil.

Este trabalho teve por objetivo descrever, de forma participativa com agricultores, a atividade de criação tradicional e avaliar a introdução de novas técnicas de manejo para a criação racional da espécie Melipona fasciculata Smith 1858, localmente conhecida como uruçucinzenta, entre os criadores de abelhas da Comunidade da Flecheira, Município de Bragança, PA.

\section{Material e Métodos}

Nos meses de junho a dezembro de 2002, foi iniciada uma série de transferências de colônias de abelhas de caixas rústica (caboclas) para caixas de criação racional. Foram selecionados dois criadores com tradição no manejo de abelhas, dispostos a absorver novos ensinamentos e a colaborarem, através de pesquisa participativa, com a equipe de pesquisadores da Embrapa Amazônia Oriental.

Para cada criador foram confeccionadas 20 caixas racionais verticais do modelo Portugal-Araújo (1955), com modificações introduzidas por Fernando Oliveira (Oliveira e Kerr 2000) e Giorgio Venturieri (Venturieri 2003) (figuras 2 e 3 ). As caixas foram confeccionas por uma marcenaria experiente, em madeira da espécie conhecida como lourovermelho (Sextonia rubra - Lauraceae). Com ajuda dos agricultores, as caixas foram montadas no local com cola e pregos e pintadas externamente com tinta acrílica branca ou verde-clara.

Para essas caixas foram transferidas 15 famílias oriundas de caixas caboclas do meliponário de dois agricultores residentes na Comunidade da Flecheira, Município de Bragança, PA. Cinco caixas foram reservadas para que futuramente fossem realizados desmembramentos destes ninhos transferidos.

O processo de transferência dos ninhos foi realizado com a participação direta dos agricultores, alguns de seus respectivos familiares e membros da equipe do projeto.

Adotando-se os mesmos cuidados e procedimentos descritos por Nogueira-Neto (1997, p. 164), inicialmente eram transferidos pedaços de invólucro, cera e resina para o fundo da nova caixa, imediatamente a rainha e todos os favos de cria eram também cuidadosamente transferidos. Somente dois a três potes de pólen, totalmente íntegros, eram transferidos para a nova caixa, o restante destes potes era guardado para posterior fornecimento às abelhas, quatro a cinco dias após a transferência. Os potes de mel eram deixados na caixa original, para posterior recolhimento e medição de seu volume. Parte do mel recolhido era colocado em um alimentador interno, confeccionado com copos de plástico descartáveis providos de tampa e furos em sua base, estes furos eram fechados com um tufo de algodão, possibilitando, assim, a alimentação das abelhas.

O mel contido nas caixas caboclas foi colhido, filtrado e medido seu volume para posterior comparação com o método racional. Após a coleta dos dados e de amostras, o restante do mel foi disponibilizado para comercialização pelos agricultores.

$\mathrm{O}$ volume médio de mel contido em cada pote foi obtido pela divisão do volume total de mel coletado em uma melgueira, pelo número total de potes contidos na mesma. A contagem dos potes foi auxiliada por fotografias digitais tiradas antes dos potes serem violados para a colheita do mel.

Todo o processo de transferência foi documentado fotograficamente, para posterior análise da evolução das famílias (figuras 1.c, d, e, f, g).

\section{Resultados e Discussão}

M. fasciculata ocorre no nordeste da Região Amazônica, nos Estados do Pará e Maranhão. Esta espécie é relativamente rara em áreas de terra firme, mas ainda muito abundante nas regiões de mangue, em que ainda existem bastante árvores com ocos suficientemente grandes para alojar suas famílias. Nos manguezais, a árvore onde normalmente o ninho desta abelha é encontrado chama-se siriúba ou mangue seriva (Avicennia nitida - Avicenniaceae).

Produz mel de excelente qualidade e em boa quantidade. Possui hábitos higiênicos (não coletam fezes) e armazenam seus méis em potes constituídos quase que exclusivamente de cera. Em geral, é menos agressiva do que a uruçu-amarela (M. flavolineata), outra espécie comum na região, também muito utilizada pelas comunidades locais.

Tanto os agricultores como seus familiares participaram ativamente e com interesse em todo o processo de montagem, pintura e transferência das famílias de abelhas das caixas caboclas para as caixas racionais, demonstrando a facilidade em absorver a prática da meliponicultura. 

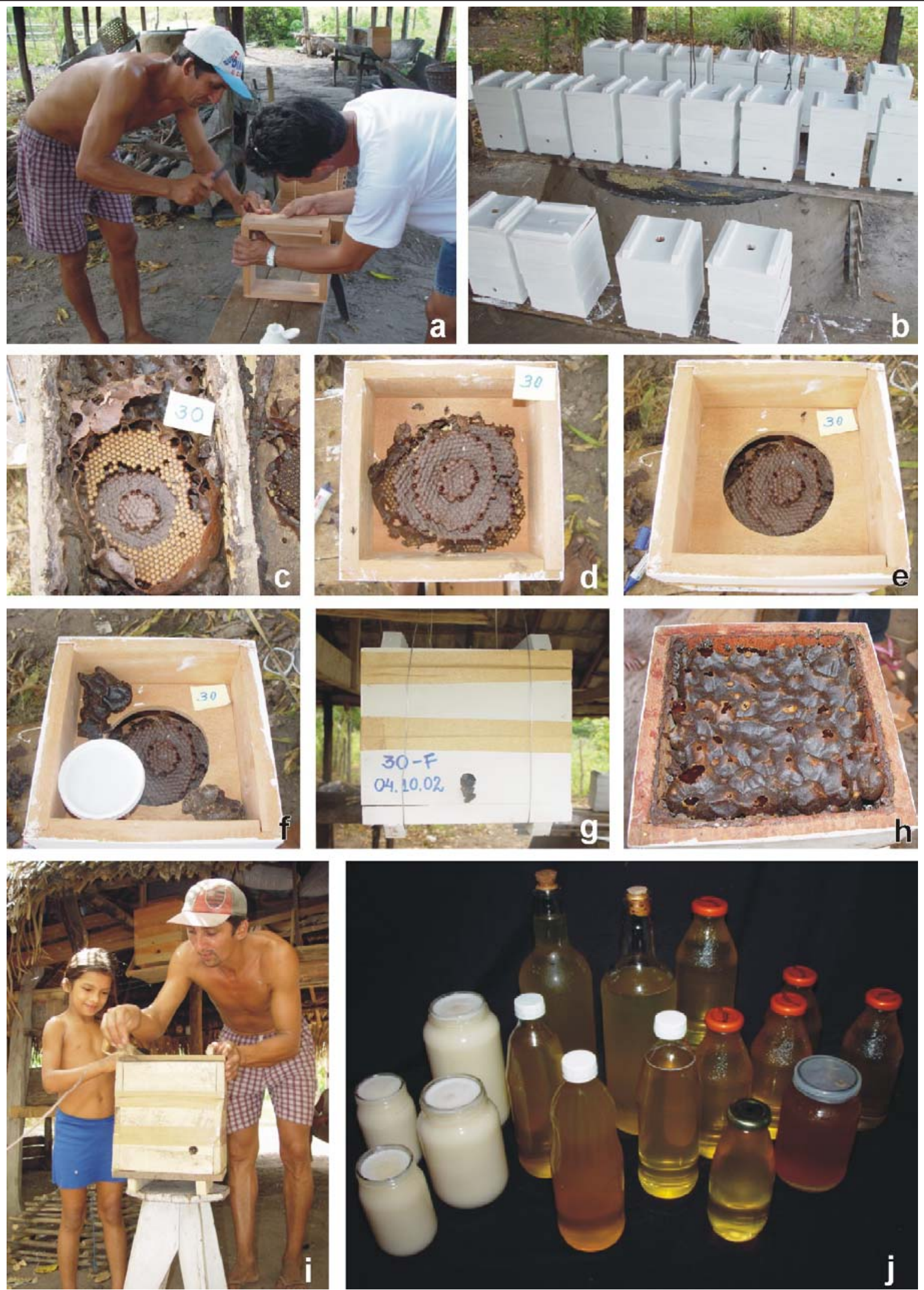

Figura 1. Transferência para caixa racional. a) montagem das caixas; b) caixas prontas, c) ninho em caixa cabocla; d) favos de cria no ninho; e) sobreninho colocado; f) sobreninho com alimentador, $g$ ) nova caixa no local definitivo: observar que nesta fase ainda não são colocadas as melgueiras, h) melgueira totalmente preenchida com potes de mel, i) a meliponicultura é de fácil assimilação pelos agricultores, e j) méis de abelhas indígenas: quando produzido de forma racional e acondicionado corretamente, resulta em um produto de excelente qualidade, alto valor nutricional e econômico. Fotografias de Giorgio Venturieri e Vanessa Raiol. 

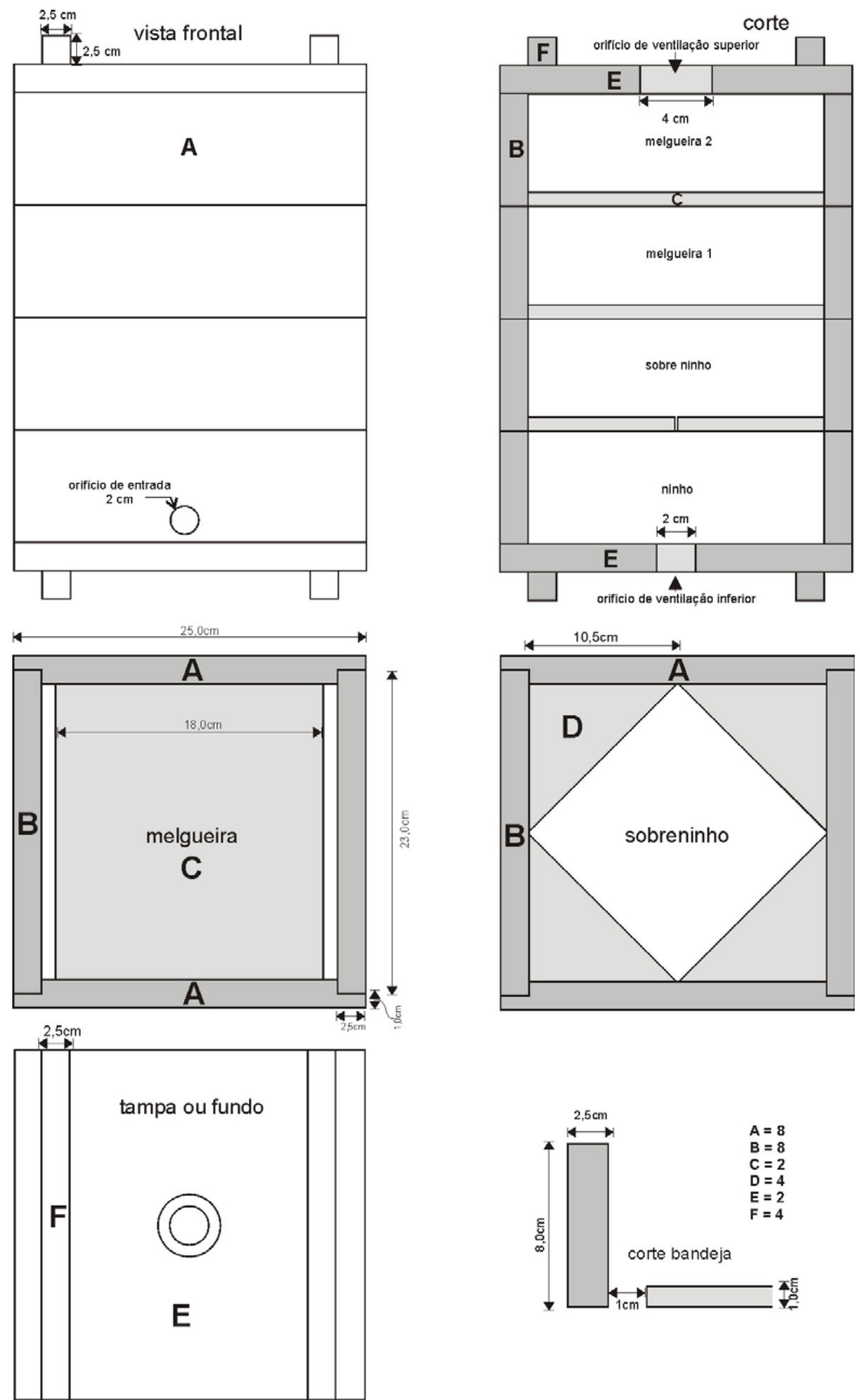

Figura 2. Caixa recomendada para criação racional de M. fasciculata no Estado do Pará. Desenho com medidas para sua confecção. Ilustração de Giorgio Venturieri. 


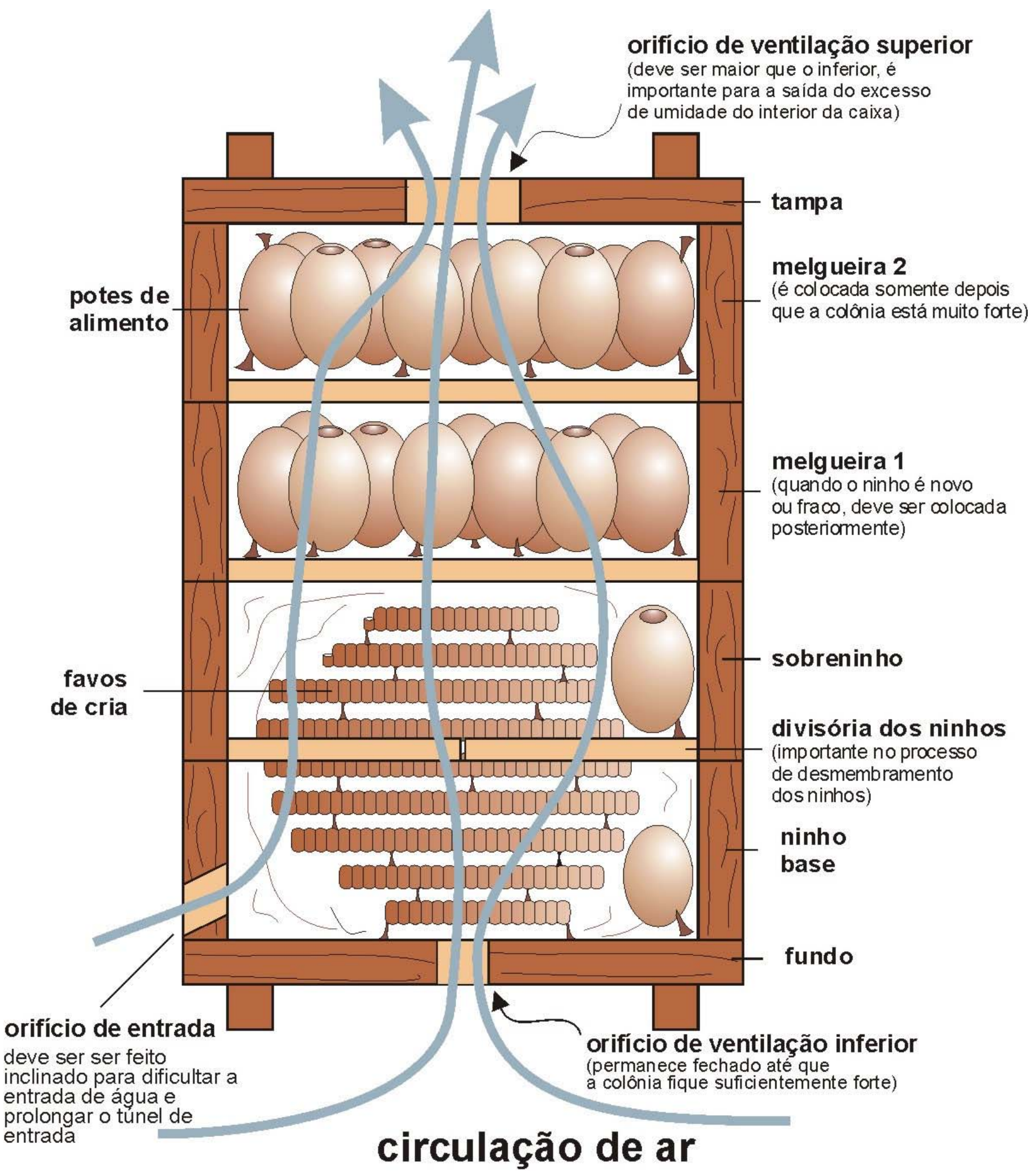

Figura 3. Caixa recomendada para criação racional de abelhas indígenas sem ferrão no Estado do Pará. Ilustração esquemática e comentada. Ilustração de Giorgio Venturieri. 
Observou-se que o processo de transferência da caixa cabocla deve ocorrer, preferencialmente, no início da florada, quando os ninhos ainda não possuem um estoque muito grande de mel e as famílias ainda não estão muito numerosas. Na região de Bragança, os meses mais indicados são junho e julho. Desta maneira, o processo é muito mais limpo, não havendo o afogamento de operárias, ou até mesmo da rainha, no mel que escorre dos potes rasgados durante a remoção dos favos de crias.

Em pelo menos três transferências ocorreu a morte da rainha pelas operárias. Provavelmente este fato tenha ocorrido em decorrência do estresse provocado pelo enorme transtorno do processo de transferência. Este fenômeno merecerá maiores estudos no futuro, contudo, é extremamente aconselhado que antes do começo da transferência dos favos, se localize e se realize a transferência em separado da rainha. Essa transferência pode ser auxiliada por pedaços de invólucro, dispostos no caminho da rainha, para que a mesma se transfira para ele, evitando-se, desta maneira, que a rainha seja esmagada ou mesmo tocada, o que poderia provocar sua rejeição na colônia, devido ao cheiro das mãos do meliponicultor.

Das 30 famílias de abelhas transferidas, somente uma morreu em decorrência de sua transferência. A morte foi ocasionada por um erro de manejo em deixar um dos alimentadores escorrendo alimento internamente pela caixa, o que atraiu formigas que liquidaram a colônia.

O volume médio de mel produzido nas caixas caboclas foi de $2.430 \mathrm{ml}(\mathrm{n}=19)$ e a produção máxima atingida em uma só colheita neste tipo de caixa foi de $4.400 \mathrm{ml}$. Neste universo de caixas, muitas eram ainda novas (desmembrada naquele ano pelo próprio agricultor) e a média apresentada não refletiu a real produtividade dessa espécie. A produção média em um grupo de caixas ocupadas há mais de um ano (47\% das caixas) gira em torno de 3.000 a $4.400 \mathrm{ml}$.

Nas figuras 2 e 3 é apresentado o desenho detalhado do modelo de caixa utilizado. Neste modelo de caixa, as abelhas são induzidas a estocar o mel nas "melgueiras", localizadas acima do ninho. Quando estas melgueiras estão totalmente preenchidas, cada uma delas pode armazenar de 1.250 a $1.350 \mathrm{ml}$ (figura 1.h). Cada melgueira pode conter de 60 a 70 potes, cada pote contém, em média, 20,45 ml de mel $(n=66)$.

Neste sistema, a colheita do mel é realizada da seguinte maneira: os potes são perfurados com uma faca, posteriormente a melgueira é virada sobre um recipiente de plástico contendo uma tela para filtragem do mel e proteção de eventuais abelhas que poderiam cair no mel.

Durante o mês de junho/2002, quatro colônias que estavam em caixas rústicas foram transferidas para caixas racionais. Até meados de dezembro/2002, foram colhidos, no total, $13.300 \mathrm{ml}$. A primeira destas caixas produziu 5.020 ml, em três colheitas realizadas nos dias 27/09/02, 12/11/02 e
27/11/02. Estes resultados são preliminares, mas já ilustram as potencialidades de aumento na produção de mel neste novo sistema de manejo, indicando que a meliponicultura poderá se tornar uma excelente alternativa na geração de renda local.

O mel das abelhas indígenas sem ferrão é comercializado localmente entre R \$10,00 e 15,00 (US\$2.94 e 4.41 , respectivamente). Estes valores representam de duas a três vezes mais daquilo que é oferecido pelo mel de Apis mellifera, outra espécie de abelha também criada na região.

Após a colheita do mel, as melgueiras foram devolvidas às suas respectivas caixas, para serem novamente trabalhadas pelas abelhas. Em uma caixa bem forte podem ser colocadas até três melgueiras, aumentandose o período entre as colheitas de mel. Contudo, recomendase para esta espécie e para as condições encontradas na localidade da Flecheira, a utilização de somente duas melgueiras com inspeções, e se for o caso, colheitas mensais.

A Comunidade da Flecheira está localizada em uma região conhecida como "Campos de Bragança", composta por grandes extensões de campos aluviais flúvio-marinhos. As espécies botânicas locais mais importantes na constituição dos méis são: caju (Anacardium occidentale Anacardiaceae), caju-açu (A. giganteum - Anacardiaceae), siriuba (Avicennia nitida - Avicenniaceae), sapateira (Miconia minutiflora - Melastomataceae) e lacre (Vismia guianensis - Clusiaceae) entre outras. O período de floração coincide com o de menores índices pluviométricos, em que na região vão de julho a dezembro. A maior produção de mel concentra-se, entretanto, de agosto a novembro.

Após o término da florada e com o início do período chuvoso (janeiro de 2003), observou-se uma acentuada redução da quantidade de potes de alimento, em que as abelhas desfizeram os potes que estavam vazios. Em uma das caixas, após a total retirada dos potes, foi observado o completo isolamento da segunda melgueira, em que as abelhas fecharam com batume (mistura de resina e solo) as frestas de acesso para esta.

Foi observado que, no período de pouca oferta de néctar, $M$. fasciculata costuma remanejar cera e cerume, engrossando as estruturas do ninho, como: pilares, invólucro e paredes dos potes remanescentes. Este fato deverá ser mais bem investigado no futuro, podendo indicar a necessidade da retirada da segunda melgueira nos períodos de pouca oferta de alimento, contribuindo com a redução do espaço não-utilizado e conseqüente controle interno da temperatura.

Desconsiderando-se a perda de uma das colônias atacadas por formigas, ocasionada muito mais por um erro de manejo do que pela incapacidade de adaptação da espécie ao método de criação racional, conclui-se que a abelha uruçucinzenta (M. fasciculata) é facilmente criada no modelo de caixa apresentado, adaptando-se muito bem ao método aqui 
testado. O sistema demonstrou ser bastante eficiente, aumentando a quantidade de mel produzido e facilitando a sua colheita.

Quanto à aceitação do método de criação racional por parte dos criadores tradicionais, pode-se concluir que foi muito boa, despertando o interesse não somente dos criadores experientes, mas também de vizinhos e outros membros da família.

A confecção de caixas de qualidade pode ser um fator de dificuldade na difusão do sistema apresentado. Portanto, é importante que oficinas e aulas de marcenaria para a confecção das caixas sejam providenciadas para as comunidades.

A meliponicultura interfere muito pouco no tempo dedicado a outras atividades praticadas pelos agricultores. O manejo dos meliponíneos é simples e exigindo pouco investimento inicial e de manutenção.

\section{Agradecimentos}

Aos criadores Eduardo e Nazareno Mesquita pelo auxílio nos trabalhos de campo e permissão de utilização de seus respectivos meliponários. Ao colega e pesquisador Joaquim Gomes (Lab. de Botânica da Embrapa Amazônia Oriental), pela identificação da madeira utilizada na confecção das caixas e das plantas apícolas. À Profa. Vera Imperatriz Fonseca (IB-USP), pelas sugestões e revisão do manuscrito. Ao Conselho de Desenvolvimento Científico e Tecnológico - CNPq, pela concessão dos recursos necessários a esta pesquisa (Processo n.COAGR/469915/00-5).

\section{Referências Bibliográficas}

HEARD, T. A. 1999. The role of stingless bees in crop plantation. Ann. Review of Entomol., v. 44, n. 183-206.

NOGUEIRA-NETO, P. 1997. Vida e criação de abelhas indígenas sem ferrão. São Paulo. Editora Nogueirapis, 446p.

OLIVEIRA, F. \& KERR, W. E. 2000. Divisão de uma colônia de japurá (Melipona compressipes manaosensis) usando-se uma colméia e o método de Fernando Oliveira. Manaus-AM: Ministério da Ciência e Tecnologia. Instituto Nacional de Pesquisas da Amazônia - INPA. 10p.

PORTUGAL-ARAÚJO, V. de. 1955. Colméias para abelhas sem ferrão - Meliponini. Bol. do Inst. de Angola. n. 7, vol.9, pg. 9-31.

SILVEIRA, F. A.; MELO, G. A. R. \& ALMEIDA; E. A. B. 2002. Abelhas brasileiras: sistemática e identificação. Belo Horizonte, MG, Min. Meio Ambiente/Fund. Araraucária. 253p.
SOARES, A. E. E. \& JONG, D. de. 1992. Pesquisas com abelhas no Brasil. Ribeirão Preto, SP. Rev. Brasileira Genética. 688p.

VENTURIERI, G. C. 2003. Meliponicultura I: Criação de Abelhas Indígenas Sem Ferrão, Caixa Racional para Criação. Belém, PA, Rec. Téc.: Embrapa Amazônia Oriental.
Título: Avaliação Da Introdução Da Criação Racional De Melipona Fasciculata (Apidae: Meliponina), Entre Os Agricultores Familiares De Bragança - Pa, Brasil

Autores: Giorgio Cristino Venturieri - Vanessa de Fátima Oliveira Raiol - Charles André Barbosa Pereira

Biota Neotropica, Vol. 3 ( número2): 2003

http://www.biotaneotropica.org.br/v3n2/pt/ abstract?article+BN00103022003

Recebido em: 28/03/2003

Publicado em: 01/08/2003

ISSN 1676-0603 